\title{
In situ Monitoring of Lysozyme Adsorption onto Bare and Cysteine- or 1-Octadecanethiol-Modified Au Electrodes Using an Electrochemical Quartz-Crystal Impedance System
}

\author{
You-yu Zhang, Qing-ji Xie, ${ }^{\dagger}$ An-hong Zhou, and Shou-zhuo Yao \\ Chemical Research Institute, Hunan Normal University, Changsha 410081, P. R. China
}

\begin{abstract}
The adsorption of lysozyme from phosphate-buffered saline $(\mathrm{pH} \mathrm{7.4)} \mathrm{onto} \mathrm{bare} \mathrm{and} \mathrm{cysteine-} \mathrm{or} \mathrm{1-octadecanethiol-}$ modified Au electrodes was investigated in situ using an electrochemical quartz-crystal impedance system (EQCIS). The equivalent circuit parameters and resonant frequencies of the piezoelectric quartz-crystal (PQC) resonance, the value of half peak width of the electroacoustic conductance spectrum $\left(\mathrm{Df}_{\mathrm{G} 1 / 2}\right)$ as well as the electrical double-layer capacitance were obtained and analyzed. The adsorption kinetics was analyzed with a scheme of two consecutive reactions occurring at the interface. The amount of adsorbed lysozyme on a hydrophobic surface was greater than that on a hydrophilic one, and a more negative potential brought a larger amount of adsorbed lysozyme. The standard heterogeneous rate constants of ferricyanide/ferrocyanide before and after the lysozyme adsorption were evaluated.
\end{abstract}

(Received February 7, 2000; Accepted April 27, 2000)

As a kind of amphiphilic substance, proteins exhibit a strong tendency to adsorb at interfaces. A study of the adsorption of proteins on a hydrophilic or hydrophobic surface and an understanding of the interaction of proteins with the solid surface are important for the development of medical devices, biotechnology and biosensors. ${ }^{1-3}$

Lysozyme is made up of 129 amino acid residues. There short segments of the chain between residues 5 and 15,24 and 34,88 and 96, have the structure of an $\alpha$-helix; the residues between 41 and 45 and 50 and 54 form pleated sheets, and a hairpin turn occurs at residues 46-49. The remaining polypeptide segments of lysozyme have a coil or loop conformation. It is a globular protein with lytic and bactericidal activity.

Piezoelectric quartz-crystal impedance (PQCI) technology has been used to study the protein and DNA adsorption. ${ }^{4,5}$ Usually, PQCI is analyzed on the basis of a Butterworth-van Dyke (BVD) equivalent electrical circuit, which consists of a motional arm and a static arm in parallel, where the static arm contains only the static capacitance $\left(C_{0}\right)$, and the motional arm contains three elements in series, namely, the motional resistance $\left(R_{1}\right)$, the motional inductance $\left(L_{1}\right)$ and the motional capacitance $\left(C_{1}\right)$, all four equivalent circuit parameters have distinct physical meanings. ${ }^{6,7}$ A modified BVD equivalent electrical circuit was proposed by using $L_{1}=L_{\mathrm{q}}+L_{\mathrm{L}}+L_{\mathrm{f}}, C_{1}=$ $C_{\mathrm{q}}$ and $R_{1}=R_{\mathrm{q}}+R_{\mathrm{L}}+R_{\mathrm{f}}$, where $C_{\mathrm{q}}, L_{\mathrm{q}}$ and $R_{\mathrm{q}}$ refer to an unperturbed crystal, ${ }^{8-10} R_{\mathrm{L}}$ and $L_{\mathrm{L}}$ are related to the liquid loading effect, $R_{\mathrm{f}}$ and $L_{\mathrm{f}}$ to the presence of the surface-bound film on the electrode. Besides the equivalent-circuit parameters, three characteristic frequencies of the piezoelectric quartz-

$\dagger$ To whom correspondence should be addressed.

E-mail: xieqj@public.cs.hn.cn crystal (PQC) resonance as follows are often used: ${ }^{11}$

$$
\begin{aligned}
& f_{0}=\frac{1}{2 \pi \sqrt{L_{1} C_{1}}}, \\
& \omega_{\mathrm{s}}^{2}=\left(2 \pi f_{\mathrm{s}}\right)^{2}= \\
& \frac{L_{1}-C_{0} R_{1}^{2}+\frac{2 L_{1} C_{0}}{C_{1}}-\sqrt{C_{0}{ }^{2} R_{1}{ }^{4}+L_{1}{ }^{2}-2 L_{1} C_{0} R_{1}{ }^{2}-\frac{4 L_{1} C_{0}{ }^{2} R_{1}^{2}}{C_{1}}}}{2 C_{0} L_{1}{ }^{2}},
\end{aligned}
$$

$$
\begin{aligned}
& \omega_{\mathrm{p}}{ }^{2}=\left(2 \pi f_{\mathrm{p}}\right)^{2}= \\
& \frac{L_{1}-C_{0} R_{1}^{2}+\frac{2 L_{1} C_{0}}{C_{1}}+\sqrt{C_{0}{ }^{2} R_{1}{ }^{4}+L_{1}^{2}-2 L_{1} C_{0} R_{1}{ }^{2}-\frac{4 L_{1} C_{0}{ }^{2} R_{1}^{2}}{C_{1}}}}{2 C_{0} L_{1}^{2}},
\end{aligned}
$$

where

$f_{0}$ is the resonant frequency at which the reactance $(\mathrm{X})$ and susceptance (B) of the motional arm vanish, $f_{\mathrm{s}}$ is the series resonant frequency, i.e. the lower frequency where the $\mathrm{X}$ and $\mathrm{B}$ of the BVD circuit vanish, and $f_{\mathrm{p}}$ is the parallel resonant frequency, i.e. the higher frequency where the $\mathrm{X}$ and $\mathrm{B}$ of the BVD circuit vanish, respectively. Note that Eqs. (1) - (3) are valid for the PQC resonance not only in the gaseous phase, but also in the liquid phase. ${ }^{11}$ The $f_{\mathrm{s}}$ and $f_{\mathrm{p}}$ equations were obtained by solving an equation that combines the conductance $(G)$ and susceptance (B) equations ${ }^{6}$ of the BVD equivalent circuit with a zero-impedance phase-angle condition, i.e., $\theta_{\mathrm{z}}=\tan ^{-1}(X / R)=$ $\tan ^{-1}(-\mathrm{B} / \mathrm{G})=0$. It is seen that both $f_{\mathrm{s}}$ and $f_{\mathrm{p}}$ are determined by all four equivalent circuit parameters, but $f_{0}$ depends only on $L_{1}$ and $C_{1}$.

A combination of the PQCI measurement with the electrochemical technology as a more powerful method than the 


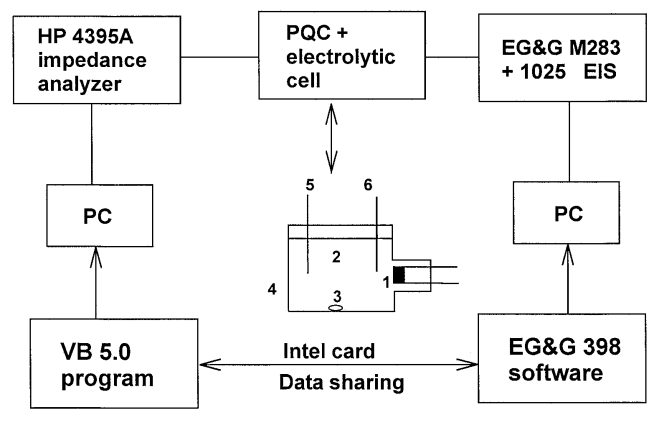

Fig. 1 Schematic representation of the EQCIS used in this work. 1: PQC sealed on one terminal of a glass tube using 704 silicon rubber adhesive; 2: test solution; 3: magnetic stirring bar; 4: glass electrolytic cell; 5: counter electrode; 6 : reference electrode with a salt bridge.

conventional electrochemical quartz-crystal microbalance (EQCM) has been used for studying metal and polymer deposition, ${ }^{9-11}$ and depletion-layer effects. ${ }^{12,13}$ To the best of our knowledge, lysozyme adsorption onto bare and modified $\mathrm{Au}$ electrodes has not been studied by such a combination technique. In this work, an electrochemical quartz-crystal impedance system (EQCIS) combining the PQCI measurement with the electrochemical impedance spectrum (EIS) measurement was thus applied to monitor lysozyme adsorption onto bare and modified gold electrodes.

\section{Experimental}

\section{Materials}

AT-cut $9 \mathrm{MHz}$ piezoelectric quartz crystals $(12.5 \mathrm{~mm}$ in diameter) were used. There was a silver electrode having a diameter of $6.0 \mathrm{~mm}$ on one side of the PQC and a gold electrode having a diameter of $6.5 \mathrm{~mm}$ on the other side of it. The gold electrode was vacuum-evaporated by using an Eiko IB-3 ion coater, and a highly pure gold foil purchased from Hitachi Inc. To remove possible surface contamination, the gold electrode surfaces were treated with $\mathrm{H}_{2} \mathrm{SO}_{4}+\mathrm{H}_{2} \mathrm{O}_{2}$ (v/v 3:1) for 5 min, rinsed thoroughly with water and then cleaned with acetoneand water-wetted filter paper, successively. Modifications of cysteine and 1-octadecanethiol were achieved by soaking the gold electrodes in a $0.005 \mathrm{~mol} \mathrm{l}^{-1}$ cysteine aqueous solution and in an acetone solution containing $0.005 \mathrm{~mol} \mathrm{l}^{-1} \quad 1$ octadecanethiol for $30 \mathrm{~min}$, respectively. Modifications of lysozyme are given in the figure captions.

Lysozyme (from chicken egg white) was purchased from Sigma and was used as received. Doubly distilled water and freshly prepared solutions were employed throughout. All experiments were carried out at room temperature.

\section{Instruments}

As shown in Fig. 1, the EQCIS used in this work included an HP 4395A network/spectrum/impedance analyzer, an EG \& G M283 + M1025 electrochemical impedance system and two IBM-compatible computers with Intel cards for data sharing. The conductance $(\mathrm{G})$ and susceptance $(\mathrm{B})$ of the PQC resonance were measured synchronously on the HP 4395A equipped with an HP 43961A impedance test adapter and an HP 16092A test fixture. A user program was written in Visual Basic (VB) 5.0 to control the HP 4395A and to acquire admittance data via an HP $82341 \mathrm{C}$ high-performance HP-IB interface card for Windows
Table 1 Values of the contact angle/degree

\begin{tabular}{cccc}
\hline $\begin{array}{c}\text { Bare Au electrode } \\
\text { surface }\end{array}$ & \multicolumn{2}{c}{ After thiol pretreatment } & $\begin{array}{c}\text { After lysozyme } \\
\text { modification }\end{array}$ \\
\cline { 2 - 3 } & Cysteine & 1-Octadecanethiol & \\
\hline 58 & & & 48 \\
57 & 44 & 111 & 49 \\
56 & & 56 \\
\hline
\end{tabular}

Values of the contact angle of the bare Au electrodes were measured after immersing these electrodes into the background electrolyte for $\mathrm{ca} .30 \mathrm{~min}$.

3.1/NT/95. The VB program included a SICL4 module from $\mathrm{HP}$ and a voice-interpretation module to produce voice message during impedance calibration of the HP 43961A impedance test adapter and compensation of the HP 16092A test fixture. Time, number of frequency scans, the series resonant frequency $\left(f_{\mathrm{s}}\right.$, i.e. the smaller frequency at zero $\mathrm{B}$, found automatically by the HP $4395 \mathrm{~A}$ with a frequency resolution of $0.001 \mathrm{~Hz}$ ) and the maximum $G$ value were displayed during measurements. A non-linear least square fitting program based on the GaussNewton algorithm was written in VB 5.0 for the simultaneous fits of $\mathrm{G}$ and $\mathrm{B}$ data.

A saturated $\mathrm{KCl}$ calomel electrode (SCE) with a supporting electrolyte salt bridge served as the reference and all potentials in this work were referenced to it. A large-area platinum plate was used as the counter electrode. The gold electrode of the PQC was placed in a test solution, connected to the ground terminal of the HP 16092A test fixture and used as the working electrode, too. The silver electrode of the PQC was placed in air and served only as the connection electrode to the nonground terminal of the HP 16092A.

\section{Measurements}

The measurement conditions of $\mathrm{G}$ and $\mathrm{B}$ were: 101 points, a frequency span of $40 \mathrm{kHz}$ covering the resonant frequency of the PQC, IF BW of $10 \mathrm{kHz}$, source power of $0.5 \mathrm{dBm}$. Prior to admittance measurements, 3-step impedance calibrations of the HP 43961A impedance test adapter (open, short and $50 \Omega$ standard loading) and 2-step compensations of the HP 16092A test fixture (open and short) were carried out. The acquisition period for admittance data was $c a .1 \mathrm{~s}$ while the HP 4395A completed each frequency scan within the given domain in $c a$. $0.11 \mathrm{~s}$ under the selected impedance measurement condition. The EIS measurement under control of EG\&G 398 EIS measurement software was conducted simultaneously during the PQCI measurement.

\section{Results and Discussion}

The surface hydrophilicity of bare and modified Au electrodes

Anchor of organic molecules on the electrode surface via covalent bonding is an effective approach for modulating the electrode surface hydrophilicity. A cysteine-modified Au electrode surface via $\mathrm{S}-\mathrm{Au}$ bonding is expected to be relatively hydrophilic because of the presence of many amino and carboxyl groups on its surface, and a 1-octadecanethiolmodified Au electrode via S-Au bonding should be relatively hydrophobic because of the presence of many long-chain alkyl groups on the electrode surface. The values of the contact angle of bare and modified Au electrodes are listed in Table 1. As expected, compared with the contact angle on the bare $\mathrm{Au}$ electrode surface, cysteine modification decreased and 1octadecanethiol modification increased the contact angle, 


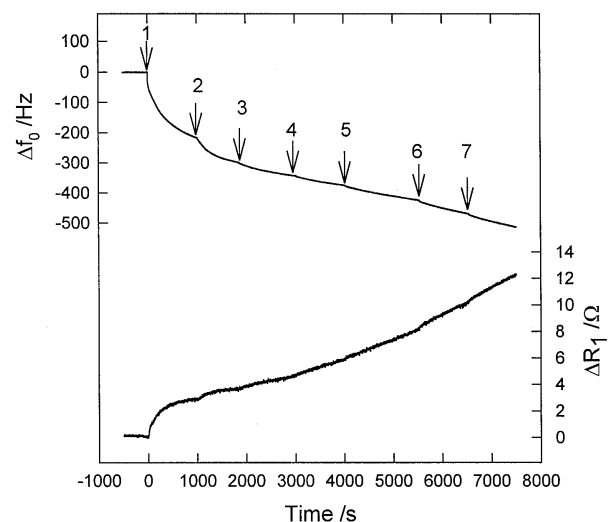

Fig. 2 Time courses of simultaneous responses of $\Delta f_{0}$ and $\Delta R_{1}$ during the adsorption of lysozyme onto a 1-octadecanethiol-modified Au electrode in $0.5 \mathrm{~mol} \mathrm{l}^{-1} \mathrm{NaCl}+0.02 \mathrm{~mol} \mathrm{l}^{-1} \mathrm{NaH}_{2} \mathrm{PO}_{4}+0.08 \mathrm{~mol} \mathrm{l}^{-1}$ $\mathrm{Na}_{2} \mathrm{HPO}_{4}$ aqueous solution ( $\mathrm{pH}$ 7.4). Arrows indicate additions of lysozyme solutions $(1.0 \mathrm{ml})$ to a final lysozyme concentration of $0.097 \mathrm{~g} \mathrm{l}^{-1}(1), 0.289 \mathrm{~g} \mathrm{l}^{-1}(2), 0.447 \mathrm{~g} \mathrm{l}^{-1}(3), 0.611 \mathrm{~g} \mathrm{l}^{-1}(4), 0.831 \mathrm{~g}$ $\mathrm{l}^{-1}(5), 1.244 \mathrm{~g} \mathrm{l}^{-1}(6), 1.472 \mathrm{~g} \mathrm{l}^{-1}(7)$, respectively.

respectively, indicating that cysteine and 1-octadecanethiol molecules were present on the $\mathrm{Au}$ electrodes with highlyordered orientation, respectively.

EQCIS measurements during lysozyme adsorption onto bare and cysteine- or 1-octadecanethiol-modified electrodes

The electrochemical interface can be represented as an electrical circuit composed of the electrolyte resistance $\left(R_{\mathrm{e}}\right)$ in series with the parallel combination of the double layer capacitance $\left(C_{\mathrm{d}}\right)$ with an impedance $\left(Z_{\mathrm{f}}\right)$. For a given frequency $(f)$ which is high enough, ${ }^{14,15}$ the electrochemical interface can be simplified as a series RC circuit $\left(Z=Z_{\mathrm{re}}-j Z_{\mathrm{im}}\right)$, and thus $R_{\mathrm{e}}$ and $C_{\mathrm{d}}$ can be calculated from the real part $\left(Z_{\mathrm{re}}\right)$ and the imaginary part $\left(Z_{\text {im }}\right)$ of the impedance $(Z)$ according to $R_{\mathrm{e}}=Z_{\mathrm{re}}$ and $C_{\mathrm{d}}=1 /\left(2 \pi f Z_{\mathrm{im}}\right)$, even if it is not really frequency independent. ${ }^{14,15}$ In this work, the electrochemical impedance was thus measured at $3 \mathrm{kHz}$.

Figure 2 shows the time courses of the simultaneous responses of $\Delta f_{0}$ and $\Delta R_{1}$ during the adsorption of lysozyme onto a 1 octadecanethiol-modified Au electrode. Upon the additions of lysozyme solutions, $\Delta R_{1}$ increased continually and could not reach a quasi-plateau region; and $\Delta f_{0}$ decreased continually and hardly reached a very steady value either. However, the responses of $\Delta f_{0}$ and $\Delta R_{1}$ did not change rapidly when the lysozyme added was over $0.447 \mathrm{~g} \mathrm{l}^{-1}$. The responses of $\Delta f_{0}$ and $\Delta R_{1}$ were also obtained for lysozyme adsorption onto a bare or cysteine-modified Au electrode, but the changes of $R_{1}$ were smaller $(<1 \Omega)$, as compared with the case of the 1 octadecanethiol-modified Au electrode, and $R_{1}$ also increased rapidly after the final concentration of lysozyme was over $c a$. $0.65 \mathrm{~g} \mathrm{l}^{-1}$. These findings may suggest different adsorption mechanisms on these electrodes, as discussed later. It should be noted that almost no changes in $\Delta f_{0}$ and $\Delta R_{1}$ were observed when an identical volume of background solution was added, indicating that the above responses of $\Delta f_{0}$ and $\Delta R_{1}$ were resulted mainly from the adsorption of lysozyme on the electrodes, rather than changes of solution density and viscosity after the lysozyme addition: $0.5 \mathrm{~g} \mathrm{l}^{-1}$ was selected as the final concentration of lysozyme in the following lysozyme adsorption experiments.

Figure 3 shows typical responses of $\Delta R_{1}, \Delta f_{0}, \Delta \mathrm{Df}_{\mathrm{G} 1 / 2}, \Delta R_{\mathrm{e}}$

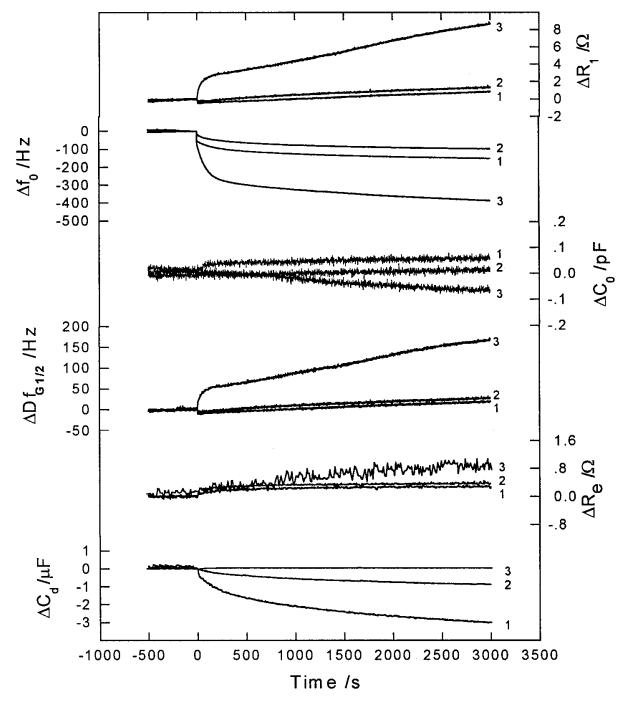

Fig. 3 Time courses of simultaneous responses of $\Delta R_{1}, \Delta f_{0}, \Delta C_{0}$, $\Delta \mathrm{Df}_{\mathrm{G} 1 / 2}, \Delta R_{\mathrm{e}}$ and $\Delta C_{\mathrm{d}}$ during the adsorption of lysozyme onto bare (1) and cysteine- (2) or 1-octadecanethiol-modified (3) Au electrodes in $0.5 \mathrm{~mol} \mathrm{l}^{-1} \mathrm{NaCl}+0.02 \mathrm{~mol} \mathrm{l}^{-1} \mathrm{NaH}_{2} \mathrm{PO}_{4}+0.08 \mathrm{~mol} \mathrm{l}^{-1} \mathrm{Na}_{2} \mathrm{HPO}_{4}$ aqueous solution $(\mathrm{pH} 7.4) .3 \mathrm{kHz}, 5 \mathrm{mV} \mathrm{rms}, 0.1 \mathrm{~V}$ vs. SCE. Lysozyme solutions $(1.0 \mathrm{ml})$ were added at time zero to a final concentration of $0.5 \mathrm{~g}^{-1}$.

and $\Delta C_{\mathrm{d}}$ obtained simultaneously during the adsorption of lysozyme onto bare and cysteine- or 1-octadecanethiol-modified $\mathrm{Au}$ electrodes, where $\mathrm{Df}_{\mathrm{G} 1 / 2}$ is the half peak width of $\mathrm{G}$ spectrum, as defined later. A $+0.1 \mathrm{~V}$ vs. SCE bias was applied during electrochemical impedance meaurements. It is seen that additions of lysozyme in all cases led to increases in $R_{1}, \mathrm{Df}_{\mathrm{G} 1 / 2}$, and $R_{\mathrm{e}}$, but to decreases in $f_{0}$. The changes in $R_{1}$ were small (within $c a .1 \Omega$ ) in the cases of lysozyme adsorption onto either bare or cysteine-modified gold electrode, but the changes in $R_{1}$ was larger for the 1-octadecanethiol-modified $\mathrm{Au}$ electrode. The motional resistance $\left(R_{1}\right)$ represents the energy dissipation of the PQC resonance into the surrounding environment. The responses of $R_{1}$ can, in principle, be understood from increases in the density and viscosity of protein layers adsorbed onto the electrode surface etc., the obvious increases of $R_{1}$ observed after adding lysozyme of a $0.5 \mathrm{~g} \mathrm{l}^{-1}$ final concentration for the 1 octadecanethiol-modified Au electrode may suggest that many $\mathrm{H}_{2} \mathrm{O}$ molecules were simultaneously introduced to the lysozyme surface film during lysozyme adsorption, resulting in an increase in the viscous effect of the surface film because of the hydrophilic increase after the lysozyme adsorption. Protein adsorption onto the surface of the bare or cysteine-modified electrode decreased $C_{\mathrm{d}}$, as reported previously, ${ }^{15}$ but lysozyme adsorption onto the surface of the 1-octadecanethiol-modified Au electrode increased $C_{\mathrm{d}}$ (Figs. 4 and 6 ). The result may be explained by the increase in the electrode surface hydrophilicity after the adsorption of lysozyme; therefore, more $\mathrm{H}_{2} \mathrm{O}$ molecules with a large value of permittivity could accumulate near the electrode surface.

According to the Sauerbrey equation, ${ }^{16}$ the mass change can be calculated out from the frequency shift $\left(\Delta f_{0}\right)$ for the rigid and thin film loading,

$$
-\Delta f_{0}=2.26 \times 10^{-6} f_{0 \mathrm{~g}} \Delta m / A,
$$

where $\Delta f_{0}$ and $f_{0 \mathrm{~g}}$ are the frequency shift and the fundamental frequency of the quartz crystal in $\mathrm{Hz}$, respectively, $\Delta m$ is the 
Table 2 Parameters obtained by fitting responses of $\Delta f_{0}$ and $\Delta C_{\mathrm{d}}$ given in Fig. 3 to Eq. (13)

\begin{tabular}{|c|c|c|c|c|c|c|c|}
\hline $\begin{array}{c}\mathrm{Au} \\
\text { electrode }\end{array}$ & Response & $a_{0}$ & $a_{1}$ & $a_{2}$ & $\tau_{1} / \mathrm{s}$ & $\tau_{2} / \mathrm{s}$ & $q_{\mathrm{r}}$ \\
\hline \multirow[t]{2}{*}{ Bare } & $\Delta f_{0} / \mathrm{Hz}$ & -162 & 44 & 69 & 129 & 1616 & $7.55 \times 10^{-5}$ \\
\hline & $\Delta C_{\mathrm{d}} / \mu \mathrm{F}$ & -3.1 & 0.93 & 2.3 & 169 & 2042 & $1.05 \times 10^{-4}$ \\
\hline \multirow[t]{2}{*}{ Cysteine-modifed } & $\Delta f_{0} / \mathrm{Hz}$ & -103 & 31 & 59 & 90 & 1279 & $1.14 \times 10^{-4}$ \\
\hline & $\Delta C_{\mathrm{d}} / \mu \mathrm{F}$ & -1.10 & 0.218 & 0.866 & 212 & 2332 & $2.35 \times 10^{-4}$ \\
\hline \multirow{2}{*}{$\begin{array}{l}\text { 1-Octadecanethiol- } \\
\text { modified }\end{array}$} & $\Delta f_{0} / \mathrm{Hz}$ & -424 & 206 & 158 & 88 & 2178 & $7.23 \times 10^{-6}$ \\
\hline & $\Delta C_{\mathrm{d}} / \mu \mathrm{F}$ & 0.055 & -0.057 & -0.087 & 63 & 1051 & $3.67 \times 10^{-4}$ \\
\hline
\end{tabular}

$a_{0}, a_{1}, a_{2}$, are in $\mathrm{Hz}$ for $\Delta f_{0}$ and in $\mu \mathrm{F}$ for $\Delta C_{\mathrm{d}}$, respectively.

mass loaded on the electrode in $\mathrm{g}$, and $A$ is the geometric area of the electrode in $\mathrm{cm}^{2}$. In order to estimate the amount of adsorbed lysozyme reasonably from the $\Delta f_{0}$ responses using the Sauerbrey equation, it is certainly very important to evaluate the non-mass effect of lysozyme adsorption on $\Delta f_{0}$, which should be reflected by the $\Delta R_{1}$ responses. The relationship between $\Delta R_{1}$ and $\Delta f_{0}$ due to the net changes in the solution density and viscosity can be obtained from Martin's equations, ${ }^{8-13}$

$$
\Delta R_{1}=-\frac{4 \pi L_{\mathrm{q}} \Delta f_{0} \sqrt{f \mu_{\mathrm{q}}}}{\sqrt{\bar{c}_{66} f_{\mathrm{og}}}} \approx-4 \pi L_{\mathrm{q}} \Delta f_{0},
$$

where $L_{\mathrm{q}}$ and $f_{0 \mathrm{~g}}$ are the motional inductance and resonant frequency of the quartz crystal in air, respectively, $\mu_{\mathrm{q}}$ is the shear modulus for the AT-cut quartz $\left(2.947 \times 10^{10} \mathrm{~N} / \mathrm{m}^{2}\right), \bar{c}_{66}$ is the lossy piezoelectrically stiffened quartz elastic constant $\left(2.957 \times 10^{10} \mathrm{~N} / \mathrm{m}^{2}\right)$ and $f_{0}$ can be approximately used in the calculation instead of $f$ with an error below $c a .0 .3 \%$. For the 9 $\mathrm{MHz}$ crystal used in this work, the slope of $\Delta f_{0}$ vs. $\Delta R_{1}$ calculated from Eq. (5) is $10.4 \mathrm{~Hz} \Omega^{-1}$, indicating that the change in liquid density and viscosity equivalent to $\Delta R_{1}$ of $1 \Omega$ is able to cause only about $10 \mathrm{~Hz}$ of $\Delta f_{0}$. If it is reasonable to assume that the viscous effect on $\Delta f_{0}$ is maximum during net changes in the solution density and viscosity (net viscosity effect), the observed $\Delta R_{1}$ response of $c a .1 \Omega$ due to the nonmass (or viscosity) effect of the surface-bound lysozyme layer will thus be expected to cause a $\Delta f_{0}$ response of only several Hz. On the basis of this assumption, since the changes in $R_{1}$ were small after the additions of lysozyme solutions for bare and cysteine-modified Au electrodes (within $1 \Omega$ ), as shown in Fig. 3, $\Delta f_{0}$ should be still a fair approximation for the measurement of the amount of adsorbed lysozyme, regardless of the simultaneous observation of $\Delta R_{1}$ of $c a .1 \Omega$. In fact, values of the dry mass of the adsorbed lysozyme were found experimentally generally below the wet mass by some $15 \%$, indicating that Sauerbrey's rigid approximation was reasonably valid to estimate the mass of lysozyme adsorbed onto bare and cysteine-modified electrodes under our experimental conditions. But a bigger and continuous increase in $R_{1}$ was observed during lysozyme adsorption onto the 1-octadecanethiol-modified electrode in our experiments, indicating the increase in the viscosity of film as explained above. If the viscous effect on frequency shift according to Eq. (5) $(c a .-87 \mathrm{~Hz})$ was deducted from the total frequency shift $(-424 \mathrm{~Hz}$, shown in Fig. 3), the frequency shift has still $-337 \mathrm{~Hz}$, but the dry frequency shift measured was only $c a$. $-220 \mathrm{~Hz}$ under our experimental condition. Therefore, it seems reasonable that $\mathrm{H}_{2} \mathrm{O}$ molecules plus an electrolyte were introduced into the surface film, leading to the frequency difference.

In addition, the viscous loading on the PQC surface leads to the increase in half peak width of the $G$ curve $\left(\mathrm{Df}_{\mathrm{G} 1 / 2}\right)$, as show in Fig. 3. The $\mathrm{Df}_{\mathrm{G} 1 / 2}$, defined as the frequency difference of the two frequency points at half peak height in the $\mathrm{G}$ spectrum, can be derived as follows:

$$
G_{\max / 2}=G_{\max } / 2=1 /\left(2 R_{1}\right),
$$

According to the admittance (Y) equation of the BVD equivalent circuit model, ${ }^{4-13}$

$$
Y=G+j B=\frac{R_{1}}{R_{1}^{2}+U^{2}}+j\left(\omega C_{0}-\frac{U}{R_{1}^{2}+U^{2}}\right),
$$

where $\omega=2 \pi f, U=\omega L_{1}-1 /\left(\omega C_{1}\right)=\left(1 / C_{1}\right)\left(\omega / \omega_{0}^{2}-1 / \omega\right)$, we obtained

$$
G_{\max / 2}=\frac{R_{1}}{R_{1}^{2}+\left(\omega L_{1}-\frac{1}{\omega C_{1}}\right)^{2}}=\frac{1}{2 R_{1}},
$$

Therefore

$$
\begin{aligned}
& \omega_{\mathrm{HG} 1 / 2}=\frac{R_{1} C_{1}+\sqrt{R_{1}^{2} C_{1}^{2}+4 L_{1} C_{1}}}{2 L_{1} C_{1}}, \\
& \omega_{\mathrm{LG} 1 / 2}=\frac{-R_{1} C_{1}+\sqrt{R_{1}^{2} C_{1}^{2}+4 L_{1} C_{1}}}{2 L_{1} C_{1}}, \\
& \operatorname{Df}_{\mathrm{G} 1 / 2}=f_{\mathrm{HG} 1 / 2}-f_{\mathrm{LG} 1 / 2}=\frac{\omega_{\mathrm{HG} 1 / 2}-\omega_{\mathrm{LG} 1 / 2}}{2 \pi}=\frac{R_{1}}{2 \pi L_{1}},
\end{aligned}
$$

where $f_{\mathrm{HG} 1 / 2}$ and $f_{\mathrm{LG} 1 / 2}$ are the higher and lower frequency at half peak height $\left(G=G_{\max } / 2\right)$ in the $\mathrm{G}$ spectrum, respectively, and all symbols are in International Unit. $\Delta \mathrm{Df}_{\mathrm{G} 1 / 2}$ also gives similar viscoelastic information to $\Delta R_{1}$.

The simplest way to consider the kinetics of lysozyme adsorption is to consider two consecutive reactions occurring at the interface: ${ }^{15}$

$$
\mathrm{A} \stackrel{k_{1}}{\longrightarrow} \mathrm{B} \stackrel{k_{2}}{\longrightarrow} \mathrm{C}
$$

The second reaction can be associated either with a modification of the structure of the adsorbed molecules in the first layer or with the adsorption of a second layer of proteins upon the first layer. Therefore, the response $(r)$ may be expressed as a sum of two exponential functions, ${ }^{15}$

$$
r(t)=a_{0}+a_{1} e^{-t / \tau 1}+a_{2} e^{-t / \tau 2}
$$

By taking $a_{0}, a_{1}, a_{2}, \tau_{1}$ and $\tau_{2}$ as estimation parameters, we fitted the $\Delta f_{0}$ and $\Delta C_{\mathrm{d}}$ responses using the nonlinear fitting 


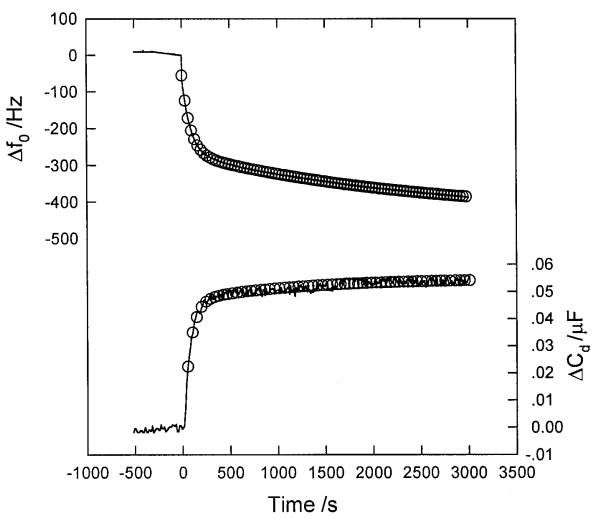

Fig. 4 Time courses of simultaneous responses of $\Delta f_{0}$ and $\Delta C_{d}$ during the adsorption of lysozyme onto the 1-octadecanethiolmodified $\mathrm{Au}$ electrode in $0.5 \mathrm{~mol} \mathrm{l}^{-1} \mathrm{NaCl}+0.02 \mathrm{~mol} \mathrm{1^{-1 }}$ $\mathrm{NaH}_{2} \mathrm{PO}_{4}+0.08 \mathrm{~mol} \mathrm{l}^{-1} \mathrm{Na}_{2} \mathrm{HPO}_{4}$ aqueous solution (pH 7.4). $3 \mathrm{kHz}, 5$ $\mathrm{mV}$ rms, $0.1 \mathrm{~V} v s$. SCE. Lysozyme solutions $(1.0 \mathrm{ml})$ were added at time zero to a final concentration of $0.5 \mathrm{~g} \mathrm{l}^{-1}$. Solid line: experimental; open circles: fitted according to Eq. (13).

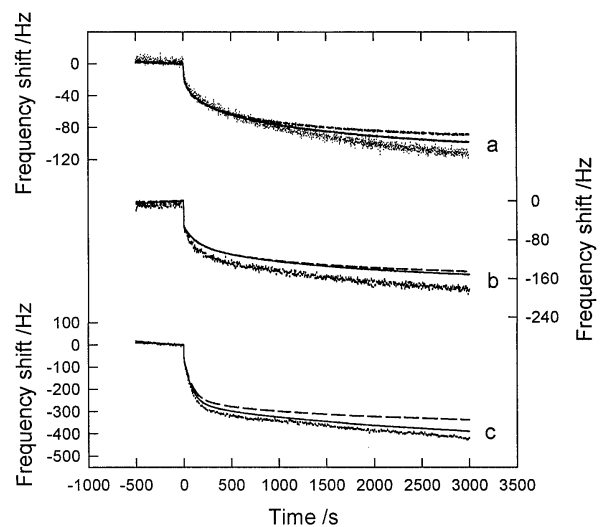

Fig. 5 Time course of simultaneous responses of $\Delta f_{0}$ (solid line), $\Delta f_{\mathrm{s}}$ (broken line) and $\Delta f_{\mathrm{p}}$ (dashed line) during adsorption of lysozyme onto cysteine-modified (a), bare (b) and 1-octadecanethiolmodified (c) Au electrodes in $0.5 \mathrm{~mol} \mathrm{l}^{-1} \mathrm{NaCl}+0.02 \mathrm{~mol} \mathrm{l}^{-1}$ $\mathrm{NaH}_{2} \mathrm{PO}_{4}+0.08 \mathrm{~mol} \mathrm{l}^{-1} \mathrm{Na}_{2} \mathrm{HPO}_{4}$ aqueous solution (pH 7.4). $3 \mathrm{kHz}, 5$ $\mathrm{mV} \mathrm{rms}, 0.1 \mathrm{~V}$ vs. SCE. Lysozyme solutions $(1.0 \mathrm{ml})$ was added at time zero to a final concentration of $0.5 \mathrm{~g} \mathrm{l}^{-1}$.

program embedded in SigmaPlot ${ }^{\circledR}$ Scientific Graphing Software Version 2.0, and the relative sum of residual square was defined as

$$
q_{\mathrm{r}}=\frac{\sum_{1}^{N}\left(r_{\mathrm{fit}}-r_{\exp }\right)^{2}}{\sum_{1}^{N} r_{\exp }^{2}},
$$

where $r_{\text {fit }}$ and $r_{\exp }$ denote the response value fitted and experimentally obtained, respectively, and $N$ is the number of response signal points.

The fitted results of $\Delta f_{0}$ and $\Delta C_{\mathrm{d}}$ are well consistent with the experimental results, as shown in Fig. 4. The results after fitting the responses of $\Delta f_{0}$ and $\Delta C_{\mathrm{d}}$ given in Fig. 3 are summarized in Table 2. According to the Sauerbrey equation, ${ }^{16}$ and the values of $a_{0}$ for $\Delta f_{0}$ listed in Table $2,-162,-103$ and $-424 \mathrm{~Hz}$ (using $-220 \mathrm{~Hz}$, i.e. the dry frequency shift in the calculation), correspond to the surface coverage of lysozyme of $0.88,0.56$ and $1.20 \mu \mathrm{g} / \mathrm{cm}^{2}$ for bare, cysteine- and 1-octadecanethiol-

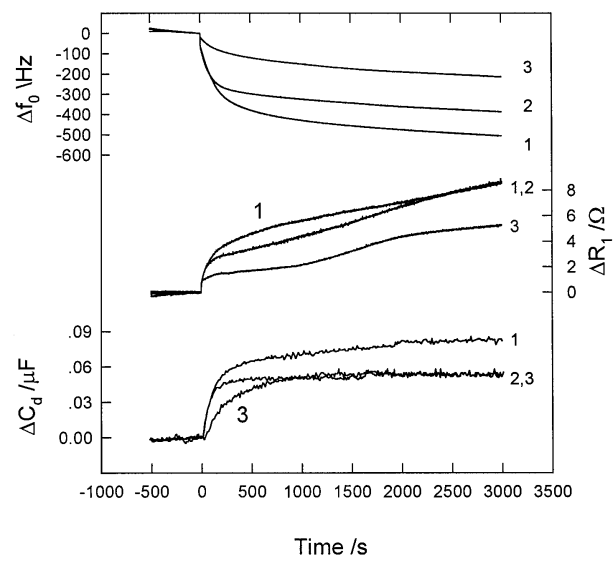

Fig. 6 Time courses of simultaneous responses of $\Delta R_{1}, \Delta f_{0}$ and $\Delta C_{\mathrm{d}}$ during the adsorption of lysozyme onto 1-octadecanethiol-modified Au electrodes at various potentials $-0.2 \mathrm{~V} \mathrm{(1)}, 0.1 \mathrm{~V} \mathrm{(2)} \mathrm{and} 0.4 \mathrm{~V}$ (3) vs. SCE in $0.5 \mathrm{~mol} \mathrm{l}^{-1} \mathrm{NaCl}+0.02 \mathrm{~mol} \mathrm{l}^{-1} \mathrm{NaH}_{2} \mathrm{PO}_{4}+0.08 \mathrm{~mol} \mathrm{l}^{-1}$ $\mathrm{Na}_{2} \mathrm{HPO}_{4}$ aqueous solution (pH 7.4). $3 \mathrm{kHz}, 5 \mathrm{mV}$ rms. Lysozyme solutions $(1.0 \mathrm{ml})$ were added at time zero to a final concentration of $0.5 \mathrm{~g} \mathrm{l}^{-1}$.

modified $\mathrm{Au}$ electrodes, respectively. Different values of surface coverage of lysozyme should imply different adsorption mechanisms, as given as follows. Protein is made up of charged area, hydrophilic area and hydrophobic area. Therefore, there are three ways that a protein interacts with a solid surface. Proteins are generally anchored on a non-charged surface via the interaction of the protein's hydrophobic terminals with hydrophobic surface or the interaction of the protein's hydrophilic terminals with hydrophilic surface. Because a 1octadecanethiol-modified Au electrode exhibited a hydrophobic surface, lysozyme molecules were anchored on the electrode surface via their hydrophobic terminals (alkyl moieties). This interaction was larger than those of hydrophilic terminals of protein with the hydrophilic surface. So the coverage of lysozyme adsorbed on the cysteine-modified Au electrode was smaller than that on the bare and 1-octadecanethiol-modified $\mathrm{Au}$ electrodes.

$\Delta C_{0}$ has been related to the double-layer capacitance of the charged surface. ${ }^{4}$ However, the present results prove that $\Delta C_{0}$ is not a direct measure of the double-layer capacitance, and may also be determined by other factors which are unclear at present.

The series resonant frequency $\left(f_{\mathrm{s}}\right)$ and the parallel resonant frequency $\left(f_{\mathrm{p}}\right)$ have been used to analyze protein adsorption. Figure 5 shows responses of $f_{\mathrm{s}}$ and $f_{\mathrm{p}}$ from the experimental results shown in Fig. 3, together with the responses of $f_{0}$ as comparisons. $f_{\mathrm{p}}$ is highly sensitive toward the structure of the electrode with the solution interface ${ }^{4,17}$ and $f_{\mathrm{s}}$ is equivalent to the oscillating frequency monitored by a conventional quartzcrystal microbalance driven by an ideal oscillation circuit. Accordingly, if $R_{1}$ and $C_{0}$ reflect, to some extent, changes in the interfacial properties and the structures of surface-confined species, responses of $f_{\mathrm{p}}$ are expected to be more sensitive to them, too. As expected, the sensitivities of the three frequencies follow the sequence $-\Delta f_{\mathrm{p}}>-\Delta f_{0}>-\Delta f_{\mathrm{s}}$, although experimentally and theoretically $f_{\mathrm{p}}>f_{\mathrm{s}}>f_{0}$. However, the change in each of the equivalent circuit parameters contributes to the responses of $\Delta f_{\mathrm{p}}$ and $\Delta f_{\mathrm{s}}$, and thus analyses of $\Delta f_{\mathrm{p}}$ and $\Delta f_{\mathrm{s}}$ are much more complicated compared with those of $\Delta f_{0}$. Generally, $\Delta f_{0}$ rather than $\Delta f_{\mathrm{p}}$ and $\Delta f_{\mathrm{s}}$, was used to evaluate the mass effect, as theoretically predicted by Martin et al. ${ }^{8}$ 

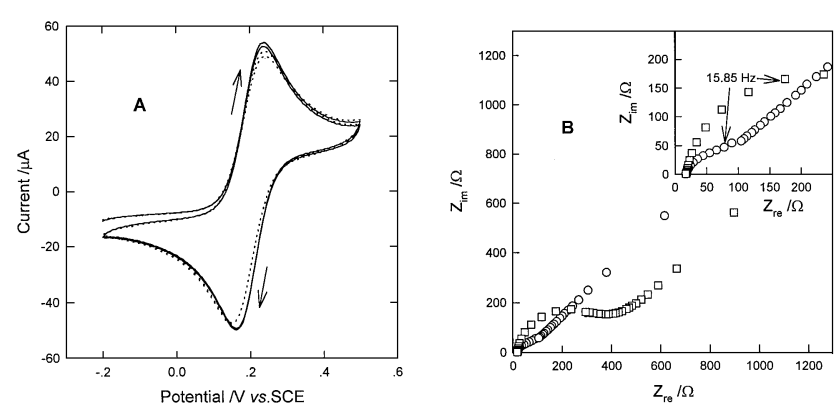

Fig. 7 Cyclic voltammograms (A) for bare (solid line) and lysozymemodified (dashed line) Au electrodes as well as electrochemical impedance spectra (B) for bare ( $\mathrm{O}$ ) and lysozyme-modified ( $\square$ ) Au electrodes in $1 \mathrm{mmol} \mathrm{l}^{-1} \mathrm{~K}_{4} \mathrm{Fe}(\mathrm{CN})_{6}+1 \mathrm{mmol} \mathrm{l}^{-1} \mathrm{~K}_{3} \mathrm{Fe}(\mathrm{CN})_{6}+0.5 \mathrm{~mol}$ $l^{-1} \mathrm{NaCl}+0.02 \mathrm{~mol} \mathrm{l}^{-1} \quad \mathrm{NaH}_{2} \mathrm{PO}_{4}+0.08 \mathrm{~mol} \mathrm{l}^{-1} \quad \mathrm{Na}_{2} \mathrm{HPO}_{4}$ aqueous solution (pH 7.4). Figure 7A, $\mathrm{d} E / \mathrm{d} t=20 \mathrm{mV} / \mathrm{s}$; Figure 7B, $100 \mathrm{kHz}$ $26.54 \mathrm{mHz}, 5 \mathrm{mV} \mathrm{rms}, 0.215 \mathrm{~V} v s$. SCE. The lysozyme adsorption experiment is shown in Fig. 3.
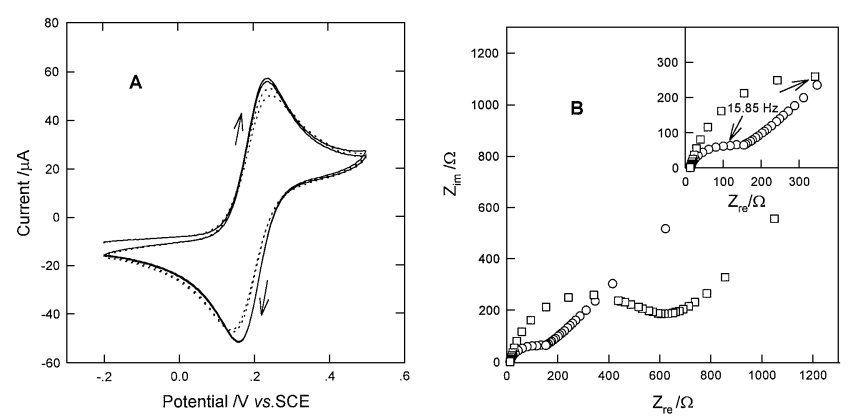

Fig. 8 Cyclic voltammograms (A) for cysteine-modified (solid line) and cysteine/lysozyme-modified (dashed line) Au electrodes as well as electrochemical impedance spectra (B) for cysteine-modified ( O ) and cysteine/lysozyme-modified ( $\square$ ) in $1 \mathrm{mmol} \mathrm{l}^{-1} \mathrm{~K}_{4} \mathrm{Fe}(\mathrm{CN})_{6}+1$ mmol $1^{-1} \mathrm{~K}_{3} \mathrm{Fe}(\mathrm{CN})_{6}+0.5 \mathrm{~mol} \mathrm{l}^{-1} \mathrm{NaCl}+0.02 \mathrm{~mol} \mathrm{l}^{-1} \mathrm{NaH}_{2} \mathrm{PO}_{4}+0.08$ mol $1^{-1} \mathrm{Na}_{2} \mathrm{HPO}_{4}$ aqueous solution ( $\left.\mathrm{pH} 7.4\right)$. Figure $8 \mathrm{~A}, \mathrm{~d} E / \mathrm{d} t=20$ $\mathrm{mV} / \mathrm{s}$; Figure 8B, $100 \mathrm{kHz}-26.54 \mathrm{mHz}, 5 \mathrm{mV}$ rms, $0.215 \mathrm{~V} v \mathrm{~s}$. SCE. The lysozyme adsorption experiment is shown in Fig. 3.

Influences of electrode potentials on the lysozyme adsorption

Lysozyme is positively charged in solutions when the solution $\mathrm{pH}$ is lower than its isoelectric point ( $c a . \mathrm{pH} 11$ for lysozyme). In solutions of $\mathrm{pH}<11$, the cationic lysozyme will be easily adsorbed on negatively charged surfaces. Figure 6 shows responses of $\Delta R_{1}, \Delta f_{0}$ and $\Delta C_{\mathrm{d}}$ obtained simultaneously during adsorption of lysozyme onto 1-octadecanethiol-modified $\mathrm{Au}$ electrodes at various potentials. The frequency shift observed at more negative potentials was larger, suggesting a larger amount of adsorbed lysozyme on the 1-octadecanethiol-modified Au electrode at more negative potentials. Generally, the responses of $\Delta R_{1}$ and $\Delta C_{\mathrm{d}}$ were also larger at more negative potentials, which can be understood because the electrode surface hydrophilicity has been increased due to adsorption of hydrophilic lysozyme molecules, and thus the uptake of more water molecules into the surface protein layer, leading to increases in both the viscosity of the surface film and the double layer capacitance.

Influence of adsorption of lysozyme on the electrode kinetics of $\mathrm{Fe}(\mathrm{CN})_{6}^{3-} / \mathrm{Fe}(\mathrm{CN})_{6}^{4-}$

Figures 7,8 and 9 show the results of potential cycling and electrochemical impedance before and after the sequential
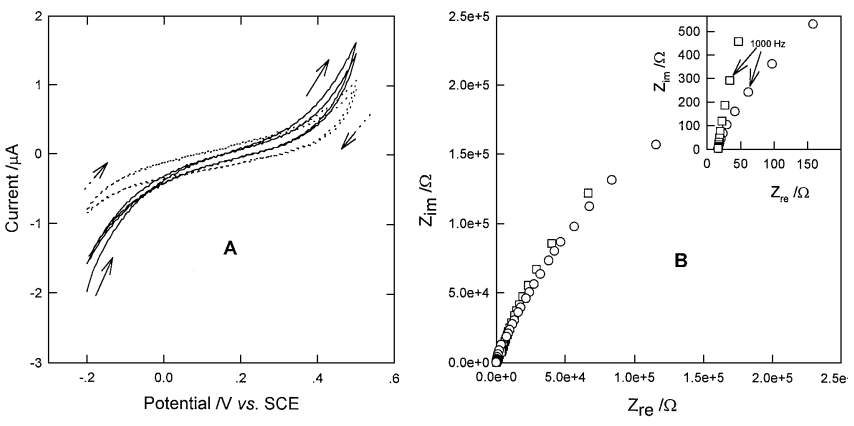

Fig. 9 Cyclic voltammograms (A) for 1-octadecanethiol-modified (solid line) and 1-octadecanethiol/lysozyme-modified (dashed line) $\mathrm{Au}$ electrodes as well as electrochemical impedance spectra (B) for 1octadecanethiol-modified ( $\mathrm{O}$ ) and 1-octadecanethiol/lysozymemodified $(\square) \mathrm{Au}$ electrodes in $1 \mathrm{mmol} \mathrm{l}^{-1} \mathrm{~K}_{4} \mathrm{Fe}(\mathrm{CN})_{6}+1 \mathrm{mmol} \mathrm{l}^{-1}$ $\mathrm{K}_{3} \mathrm{Fe}(\mathrm{CN})_{6}+0.5 \mathrm{~mol} \mathrm{l}^{-1} \mathrm{NaCl}+0.02 \mathrm{~mol} \mathrm{l}^{-1} \mathrm{NaH}_{2} \mathrm{PO}_{4}+0.08 \mathrm{~mol} \mathrm{l}^{-1}$ $\mathrm{Na}_{2} \mathrm{HPO}_{4}$ aqueous solution ( $\mathrm{pH} 7.4$ ). Figure $9 \mathrm{~A}, \mathrm{~d} E / \mathrm{d} t=20 \mathrm{mV} / \mathrm{s}$; Figure $9 \mathrm{~B}, 100 \mathrm{kHz}-26.54 \mathrm{mHz}, 5 \mathrm{mV}$ rms, $0.215 \mathrm{~V}$ vs. SCE. The lysozyme adsorption experiment is shown in Fig. 3.

Table $3 \quad k_{\mathrm{s}}$ values of $\mathrm{Fe}(\mathrm{CN})_{6}{ }^{3-} / \mathrm{Fe}(\mathrm{CN})_{6}{ }^{4}$

\begin{tabular}{lc}
\hline \multicolumn{1}{c}{ Au electrodes } & $k_{\mathrm{s}} / \mathrm{cm} \mathrm{s}^{-1}$ \\
\hline Bare & ${ }^{\mathrm{a}} 8.8 \times 10^{-3},{ }^{\mathrm{b}} 8.4 \times 10^{-3}$ \\
Lysozyme-modified & $3.4 \times 10^{-4},{ }^{\mathrm{b}} 3.6 \times 10^{-4}$ \\
& \\
Cysteine-modified & ${ }^{\mathrm{a}} 6.4 \times 10^{-3},{ }^{\mathrm{b}} 6.2 \times 10^{-3}$ \\
Lysozyme/cysteine-modified & ${ }^{\mathrm{a}} 1.5 \times 10^{-3},{ }^{\mathrm{b}} 1.6 \times 10^{-3}$ \\
1-Octadecanethiol-modified & ${ }^{\mathrm{a}} 1.4 \times 10^{-8}$ \\
Lysozyme/1-octadecanethiol-modified & ${ }^{\mathrm{a}} 1.3 \times 10^{-8}$ \\
\hline
\end{tabular}

a. From cyclic voltammogram. b. From electrochemical impedance spectra (EIS).

surface adsorption of lysozyme on the bare and cysteine- or 1octadecanethiol-modified Au electrodes. The standard rate constants $\left(k_{\mathrm{s}}\right)$ obtained from the EG\&G M271 kinetic analyses of the cyclic voltammograms and from the EIS ${ }^{14}$ are summarized in Table 3. In all cases, the adsorption of lysozyme decreased $k_{\mathrm{s}}$, owing obviously to the barrier effects of lysozyme molecules of large size. The $k_{\mathrm{s}}$ value obtained from the 1octadecanethiol-modified Au electrode is very small, suggesting that a closely-packed 1-octadecanethiol monolayer had formed on the Au surface; and the $k_{\mathrm{s}}$ decreased further after the further modification of lysozyme, demonstrating that lysozyme molecules have interacted with the 1-octadecanethiol selfassembled monolayer to produce a more closely-packed surface layer that blocked the $\mathrm{Fe}(\mathrm{CN})_{6}{ }^{3-} / \mathrm{Fe}(\mathrm{CN})_{6}{ }^{4-}$ electrode reaction more significantly.

\section{Conclusion}

The adsorption processes of lysozyme onto bare and cysteineor 1-octadecanethiol-modified $\mathrm{Au}$ electrodes were monitored simultaneously using a combination of piezoelectric quartzcrystal impedance and electrochemical impedance techniques. Equivalent-circuit parameters, resonant frequencies, the value of half peak width and the electrical double-layer capacitance have been obtained and discussed. The adsorption kinetics has been analyzed by a scheme of two consecutive reactions occurring at 
the interface. The standard heterogeneous rate constants of the ferricyanide/ferrocyanide system before and after the adsorption of lysozyme have been estimated from cyclic voltammetry and electrochemical impedance techniques. The electrochemical quartz-crystal impedance technique provides simultaneously not only electrochemical impedance information but also multidimensional piezoelectric information, it is useful for monitoring the adsorption of substances on solid surfaces.

\section{Acknowledgements}

This work was supported by the National Natural Science Foundation of China, the Teaching and Research Award Fund for Outstanding Young Teachers in Higher Education Institutions of MOE, P. R. C., the Educational Committee Foundations of China and Hunan Province as well as the Science and Technology Foundation of Hunan Province for Young Scientists.

\section{References}

1. "Surface and Interfacial Aspects of Biomedical Polymers" ed. J. D. Andrade, Vols. 1 and 2, 1986, Plenum Press, New York.

2. W. Norde, Adv. Colloid Interface Sci., 1986, 25, 267.

3. "Proteins at Interfaces", ed. J. L. Brash and T. A. Horbett, ACS symposium series 343, 1987, American Chemical
Society, Washington, D.C.

4. M. Yang, F. L. Fung, and M. Thompson, Anal. Chem., 1993, 65, 3713 .

5. M. Yamaguchi, T. Shimomura, T. Tatsuma, and N. Oyama, Anal. Chem., 1993, 65, 1925.

6. H. Muramatsu and E. Tamiya, Anal. Chem., 1988, 60, 2142.

7. M. Thompson, A. L. Kipling, W. C. Duncan-Hewitt, L. V. Rajakovic, and B. A. Cabic-Vlasak, Analyst, 1991, 116, 881

8. S. J. Martin, V. E. Granstaff, and G. C. Frye, Anal. Chem., 1991, 63, 2272

9. M. A. Noël and P. A. Topart, Anal. Chem., 1994, 66, 484.

10. H. N. Bandey, M. Gonsalves, A. R. Hillman, A. Glidle, and S. Bruckenstein, J. Electroanal. Chem., 1996, 410, 219.

11. Q. Xie, H. Liu, Y. Zhang, and S. Yao, Chin. J. Chem., 1999, 17, 491.

12. Q. Xie, J. Wang, A. Zhou, Y. Zhang, H. Liu, Z. Xu, Y. Yuan, M. Deng, and S. Yao, Anal. Chem., 1999, 71, 4649.

13. Q. Xie, J. Wang, Z. Xu, H. Liu, Y. Zhang, and S. Yao, Chem. J. Chin. Univ., 1999, 20, 549.

14. A. J. Bard and L. R. Faulkner, "Electrochemical Methods: Fundamentals and Applications", 1980, John Wiley \& Sons, New York.

15. P. Bernabeu, L. Tamisier, A. DE Cesare, and A. Caprani, Electrochim. Acta, 1988, 33, 1129.

16. G. Sauberbuey, Z. Phys., 1959, 155, 206.

17. M. Yang and M. Thompson, Anal. Chim. Acta, 1992, 269. 167. 